\title{
Volatile element composition of the upper mantle: insights from multi- isotope analyses of Mid-Atlantic Ridge popping rocks
}

\author{
DAVID V BEKAERT, PETER H BARRY, JOHN A KRANTZ, \\ JOSHUA CURTICE, ALAN M SELTZER, JUREK \\ BLUSZTAJN AND MARK D KURZ \\ Woods Hole Oceanographic Institution \\ Presenting Author: dbekaert@whoi.edu
}

The rocky building blocks that formed our planet were composed of variable amounts of volatile elements (e.g., water, carbon, nitrogen; [1]) that were subsequently reshuffled through geological processes (i.e., subduction and volcanism) to shape the habitable Earth. The accretion and degassing history of terrestrial mantle reservoirs can be probed by analyzing mantlederived samples (i.e., rocks, minerals and gases), potentially revealing the evolutionary history of terrestrial volatiles [2]. However, very few samples and volcanic localities worldwide offer clear insights into the composition of their mantle sources, and so assessing the extent of intra- and inter-reservoir variability in the solid Earth remains challenging.

Due to their extremely high volatile contents, the so-called "popping rocks" collected along the Mid-Atlantic Ridge are often regarded as the most representative samples of undegassed magmas from the upper mantle [3-5]. However, the formation mechanism(s) of these popping rocks and their suitability for characterization of the volatile element inventory of the upper mantle remain unclear [6]. Here, we present multi-isotope $(\mathrm{C}, \mathrm{N}$, noble gas, $\mathrm{Pb}, \mathrm{Sr}, \mathrm{Nd}$ ) data from "popping" and related "nonpopping" rocks collected during the 2016 and 2018 R/V Atlantis cruises to the Mid-Atlantic Ridge near $14^{\circ} \mathrm{N}$. The results reveal significant variability in $\mathrm{C}\left(\delta^{13} \mathrm{C}_{/ \mathrm{PDB}}\right.$ from $-14 \%$ to $-3 \%$ ) and $\mathrm{N}$ $\left(\delta^{15} \mathrm{~N}_{/ \text {air }}\right.$ from $-7 \%$ to $-2 \%$ ) isotopes, as well as markedly heterogeneous $\mathrm{C}-\mathrm{N}$-noble gas abundance ratios. Taken together, these data are used to investigate the genetic link between "popping" and "non-popping" rocks from the same location, (ii) constrain the processes (e.g., gas loss, bubble accumulation) and potential isotopic effects associated with popping rock generation, and (iii) deconvolute mantle source signals from secondary processes. By comparing these results with other proxies for the upper mantle composition (e.g., analysis of $\mathrm{CO}_{2}$ rich gases from intraplate volcanism [7]), we assess the extent of geochemical heterogeneities in the upper mantle and derive best estimates for its volatile element isotopic and elemental bulk composition.

[1] Piani et al.(2020) Science; [2] Mukhopadhyay \& Parai(2019) AREPS; [3] Moreira et al.(1999) Science; [4] Péron et al.(2019) EPSL; [5] Parai \& Mukhopadhyay(2021) GCA; [6] Jones et al.(2019) EPSL; [7] Bekaert et al.(2019) EPSL. 